Communications in Physics, Vol. 25, No. 4 (2015), pp. 341-347

DOI:10.15625/0868-3166/25/4/6759

\title{
CHARACTERIZATION OF ZnO:AI DEPOSITED BY CO-SPUTTERING FOR TRANSPARENT CONDUCTIVE ELECTRODES
}

\author{
NGUYEN TRAN THUAT, BUI BAO THOA, THAN THI CUC, NGUYEN MINH HIEU, \\ HOANG NGOC LAM HUONG, AND BUI VAN DIEP \\ Nano and Energy Center, VNU University of Science, 334 Nguyen Trai, Thanh Xuan District, \\ Hanoi, Vietnam \\ HOANG CHI HIEU \\ Faculty of Physics, VNU University of Science, 334 Nguyen Trai, Thanh Xuan District, Hanoi, \\ Vietnam
}

E-mail: thuatnt@vnu.edu.vn

Received 29 November 2015

Accepted for publication 24 December 2015

\begin{abstract}
Aluminum doped zinc oxide was prepared by magnetron sputtering methods at room temperature using a $\mathrm{ZnO}$ ceramic target doped $2 \%$ wt by $\mathrm{Al}_{2} \mathrm{O}_{3}$. The optical transmittance of the films is higher than $80 \%$ in the visible range. A direct bandgap type was reached by controlling deposition conditions; the bandgap value was in the range between $3.2 \mathrm{eV}$ and $4.2 \mathrm{eV}$. Good electrical and optical properties were obtained for the films deposited by an appropriate cosputtering of $\mathrm{ZnO}$ and Al targets. These films with a resistivity, about $1.3 \times 10^{-2} \Omega . \mathrm{cm}$, and a transmittance, higher than $80 \%$, can be applicable for transparent conducting electrodes.
\end{abstract}

Keywords: AZO thin film, co-sputtering method, resistivity, transmittance .

\section{INTRODUCTION}

Transparent conductive oxides (TCOs) have been extensively studied because they are essential elements for optoelectronic applications such as thin film solar cells [1], flat-panel displays [2] and light emitting diodes [3,4]... For these applications, the average optical transmittance is up to $80 \%$ in the visible range. At the presence, the commonly used TCO material is indium tint oxide (ITO), and there are growing concerns are due to its toxicity, high cost and the limited availability of the element indium [5].

Aluminum doped zinc oxide ( $\mathrm{ZnO}: \mathrm{Al}$ or $\mathrm{AZO})$ thin films are attracted a lot of intentions in the research community due to the optical properties having a sharp ultra violet(UV) cut-off. Highly transparent AZO thin films in the visible range even exhibit the low conductivity varying from $9.8 \times 10^{-2} \Omega \mathrm{cm}$ to $1.5 \times 10^{-4} \Omega \mathrm{cm}$. Furthermore, because of their chemical stability and their adhesion to the substrate, AZO films are more useful in the fabrication of thin-film solar cells. Several deposition techniques are used to grow $\mathrm{ZnO}$ :Al thin films, including chemical vapour (C)2015 Vietnam Academy of Science and Technology 
deposition (CVD) [6], spray pyrolysis [7], pulsed laser deposition (PLD) [8], pulsed magnetron sputtering [9] and conventional magnetron sputtering [10-12]. Compared to other techniques, conventional magnetron sputtering showed many advantages, such as large area smoothly thin film and relatively high growth rate.

It was reported that the conductivity of AZO films could be mostly controlled by Al concentration, which was easily adjusted by sputtering power set and time. Alnajjar confirmed that the ratio of mixture between $\mathrm{ZnO}$ and $\mathrm{Al}_{2} \mathrm{O}_{3}$ about 98:2 ensured good electrical properties [9]. Other studies showed that the AZO resistivity was the lowest when the Al concentration was different from $2 \%$ of weight. In this paper, a complete experimental optical and electrical study of AZO thin films is presented for applications in low cost oxide semiconductor based solar cells.

\section{EXPERIMENTS}

In this study, AZO thin films were deposited on silicon and corning substrates by using various sputtering techniques. Commercial 2-inch of diameter $\mathrm{AZO}\left(2 \%\right.$ weight of $\left.\mathrm{Al}_{2} \mathrm{O}_{3}\right)$ and $\mathrm{Al}$ targets are used. The oxide target is fabricated by pressing at high temperature the corresponding oxide thin powder. Four series of AZO thin films were fabricated by magnetron sputtering with: (i) only the $\mathrm{AZO}$ target, (ii) the $\mathrm{AZO}$ and the $\mathrm{Al}$ target under an oxygen reactive plasma, (iii) the $\mathrm{AZO}$ and the Al target with multiple 2-minute duration of the direct current (DC) sputter power and with/without post annealing. For the latter series, each 2 min of duration of DC sputter power was distributed equally during the whole process. All of the samples were deposited on a Syskey 2-DC and 2-radio frequency (RF) magnetron gun system. The optical properties of all the thin films were characterized on a spectroscopic ellipsometer, SmartSE Horiba-Jobin Yvon and on an ultra violet visible near infrared (UV-VIS-NIR) spectrometer, Jasco V670. The sheet resistance of thin films was measured on a four-point prober, Jandel RM3000. The thicknesses of the films were characterized also on a stylus profiler, Bruker Dektak XT system.

Table 1. The sputter conditions of various AZO thin films series

\begin{tabular}{|c|c|c|c|}
\hline $\begin{array}{l}\text { Deposition } \\
\text { parameters }\end{array}$ & $\begin{array}{l}\mathrm{AZO} \\
\text { series }\end{array}$ & $\begin{array}{l}\text { Oxygen reactive } \\
\text { AZO series }\end{array}$ & AZO with more aluminum series \\
\hline Target & $\mathrm{AZO}$ & & $\mathrm{AZO} \mathrm{Al}$ \\
\hline RF power & 30 to $90 \mathrm{~W}$ & & $90 \mathrm{~W}$ at $\mathrm{AZO}$ target \\
\hline DC power & N/A & $90 \mathrm{~W}$ at $\mathrm{Al}$ & $45 \mathrm{~W}$ at $\mathrm{Al}$ target \\
\hline Time & $1 \mathrm{~h}$ & $30 \mathrm{~min}$ & $\begin{array}{l}\text { 1h for RF } \\
\text { Multiple of 2-minute duration for DC }\end{array}$ \\
\hline Base pressure & \multicolumn{3}{|c|}{$<5 \times 10^{-6}$ Torr } \\
\hline Sputter pressure & \multicolumn{3}{|c|}{$9.10^{-3}$ Torr } \\
\hline Ar flow rate & \multicolumn{3}{|r|}{$20 \mathrm{sccm}$} \\
\hline O2 flow rate & N/A & 1 to $2 \mathrm{sccm}$ & N/A \\
\hline Substrate & \multicolumn{3}{|c|}{ Silicon and corning glass } \\
\hline $\begin{array}{l}\text { Target-substrate } \\
\text { distance }\end{array}$ & \multicolumn{3}{|r|}{$10 \mathrm{~cm}$} \\
\hline $\begin{array}{l}\text { Post deposition } \\
\text { annealing }\end{array}$ & & & $\begin{array}{l}500^{\circ} \mathrm{C} \text {, under } 5.10^{-2} \text { Torr of } \\
5 \% \mathrm{H}_{2} \text { in } \mathrm{Ar}\end{array}$ \\
\hline
\end{tabular}




\section{RESULTS AND DISCUSSION}

Fig. 1 shows the dependence of AZO thin films deposition rate as function of the RF power. The thickness of the films is deduced by spectroscopic ellipsometer adjustment by using the mixture of $\mathrm{ZnO}$ (98\% of weight) and $\mathrm{Al}_{2} \mathrm{O}_{3}$ (2\% of weight) materials provided by the DeltaPsi2 software. The details of the adjustments are not shown here; only the thickness of the main layer is used for calculating the deposition rate. From Fig. 1, one can easily sees that when the RF sputter power increases from $30 \mathrm{~W}$ to $90 \mathrm{~W}$, the deposition rate increases from about $15 \AA / \mathrm{min}$ to about 35 $\AA / \min$.

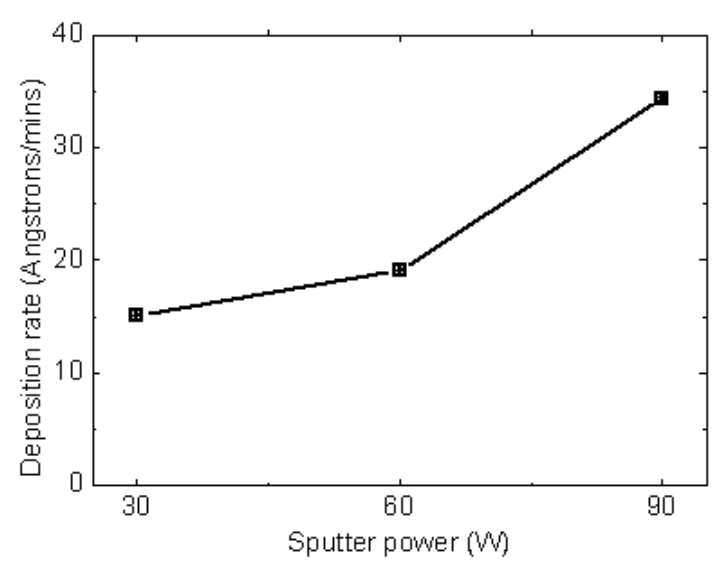

Fig. 1. The RF-power dependence of the deposition rate of AZO thin films

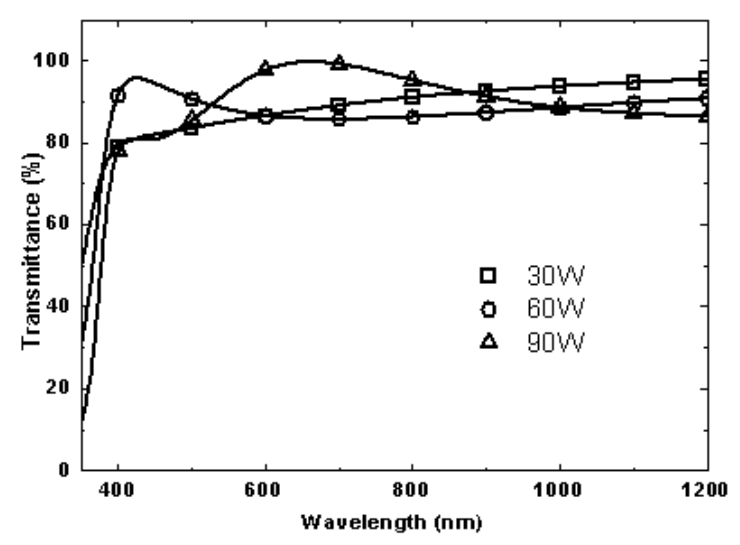

Fig. 2. Transmittance spectra of AZO thin films vs. RF powers

Fig. 2 shows the transmission spectra of AZO thin films deposited at different RF sputter power. The average transmittance of these films is generally higher than $80 \%$, thus showing its good transparent properties for the range of wavelength higher than $400 \mathrm{~nm}$. One can see the peak feature of the spectra. However these peaks correspond to the interference effect of the light.

In order to deduce the band gap of the AZO thin films, the absorption coefficient of the films is calculated from the transmittance spectra with thickness provided by spectroscopic ellipsometer. Fig. 3 shows the dependence of $(\alpha h v)^{2}$ curves versus photon energy. At higher photon energy, the linear feature is observed, giving the way to extrapolate the Tauc band gap of the AZO thin films [13]. The extrapolation indicates that the direct band gap value is between $3.2 \mathrm{eV}$ and $3.3 \mathrm{eV}$ which corresponds to the transparent window showed at Fig. 2.

The synthesis of AZO is further studied by more complicated reactive co-sputter techniques. An additional $\mathrm{Al}$ target is used and a small quantity of oxygen gas is introduced with $\mathrm{Ar}$ for the reactive sputtering process. At this experiment, the RF power is kept fixed at $90 \mathrm{~W}$ on the AZO target; the DC power on the $\mathrm{Al}$ target is also fixed at $60 \mathrm{~W}$. For this series, only oxygen flow rate is changed from $5 \%$ to $10 \%$ of the total gas flow rate, which is constant at $20 \mathrm{sccm}$. Fig. 4 shows the deposition rate of AZO thin films as function of the oxygen flow rate ratio. We can see that the deposition rate decreases slightly, from $75 \AA / \mathrm{min}$ to about $50 \AA / \mathrm{min}$ as the oxygen flow rate increases. These deposition rates are generally higher than those when only the AZO target is used. This is the direct result of the reactive sputtering process on the additional $\mathrm{Al}$ target. 


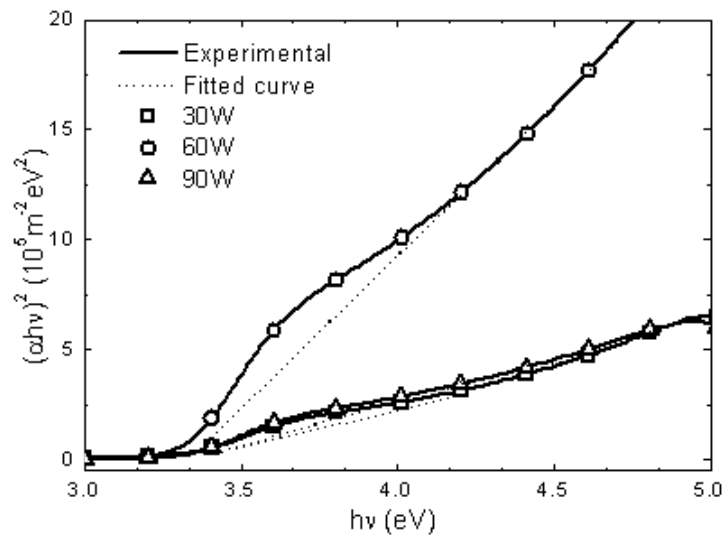

Fig. 3. The $(\alpha h v)^{2}$ curves vs. the photon energy for AZO/glass thin film.

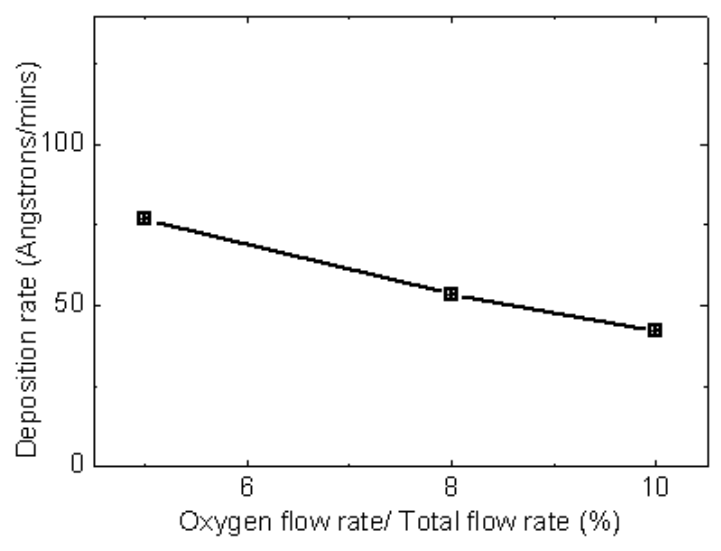

Fig. 4. The deposition rate of the oxygen reactive AZO series with different oxygen flow rate ratio

Fig. 5 shows the transmission spectra of thin films obtained by the oxygen reactive cosputter method with different oxygen flow rate ratio. It can be seen clearly that the overall transmission of these thin films is higher than $90 \%$. These films are in fact more transparent than thin films obtained by sputtering only the AZO target (showed by Fig. 2). By adding more $\mathrm{Al}$ and under the oxygen reactive plasma, the films exhibit more enhancements of the transparent effect, which may give the drawback of the conductive properties.

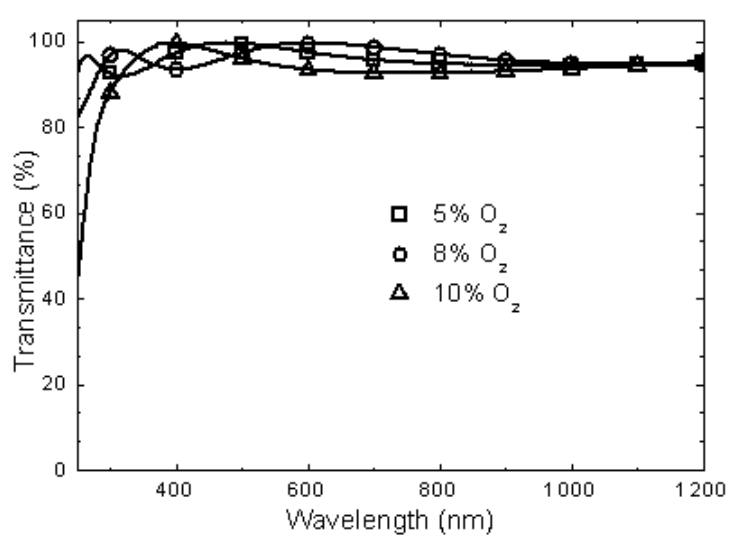

Fig. 5. The transmittance spectra of oxygen reactive co-sputtered AZO thin films at different oxygen flow rate ratio

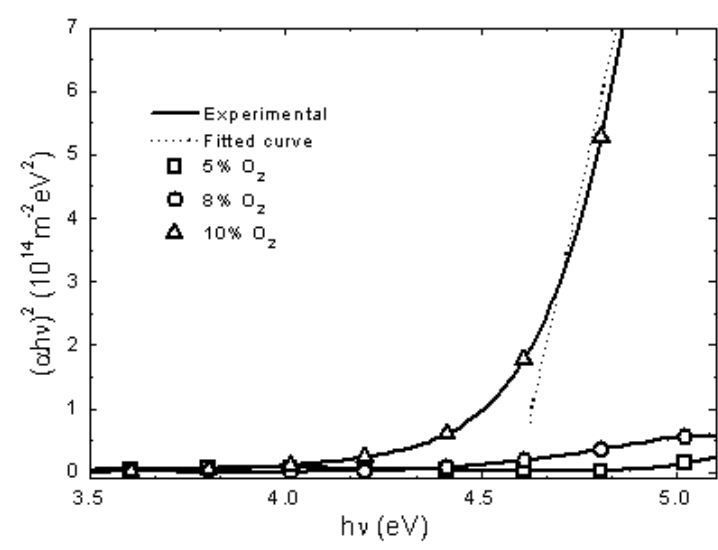

Fig. 6. The extrapolation of bandgap of oxygen reactive co-sputtered AZO thin films

Fig. 6 show the $(\alpha h v)^{2}$ curves versus photon energy of the films obtained by the oxygen reactive co-sputtering method. From the linear fit of the curves, the bandgap is then extrapolated. It is found that this band gap varies from about 4.3 to $4.5 \mathrm{eV}$. 
In order to enhance the conductive properties of AZO thin films, aluminum was added by using another co-sputtering method. For this series of experiment, the RF power on the AZO target is kept constant at $90 \mathrm{~W}$, only Ar is used for reducing the oxidation effect during the sputtering. The DC power on the $\mathrm{Al}$ target is ignited during a limited numbers of 2 min duration for $1 \mathrm{~h}$ of sputtering time. 4 min condition corresponds to 2 times the DC power is ignited during $2 \mathrm{~min}$ each, equally distributed during 1 hour. 6 min corresponds to 3 times the DC power is on during 2 min. The more time DC power on Al target is ignited, the more aluminum is added to the films.

The conductive effect of the obtained films is further enhanced by the annealing process just after sputtering, at $500^{\circ} \mathrm{C}$ under $5 \times 10^{-2}$ Torr of $5 \%$ hydrogen in Ar gas mixture. The presence of the hydrogen is supposed to passivate dangling bonds of the films, thus giving a raise to the conductivity. Fig. 7 shows the deposition rate of AZO thin film as function of the DC sputter time on the $\mathrm{Al}$ target. One can see that this value stays relatively stable, at about $25 \AA / \mathrm{min}$ to 30 $\AA / \mathrm{min}$ as the DC power time increases from 0 to $6 \mathrm{~min}$. The thicknesses of these films are in fact confirmed by the measurement on a stylus profilometer.

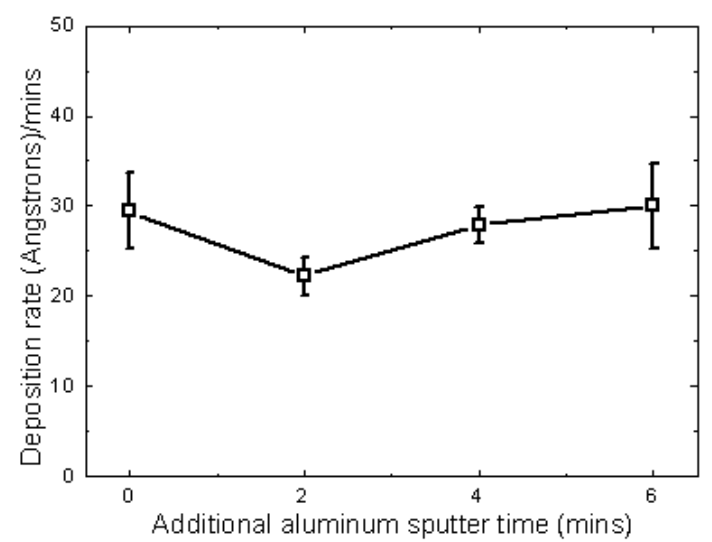

Fig. 7. The deposition rate of AZO vs. aluminum co-sputtering time

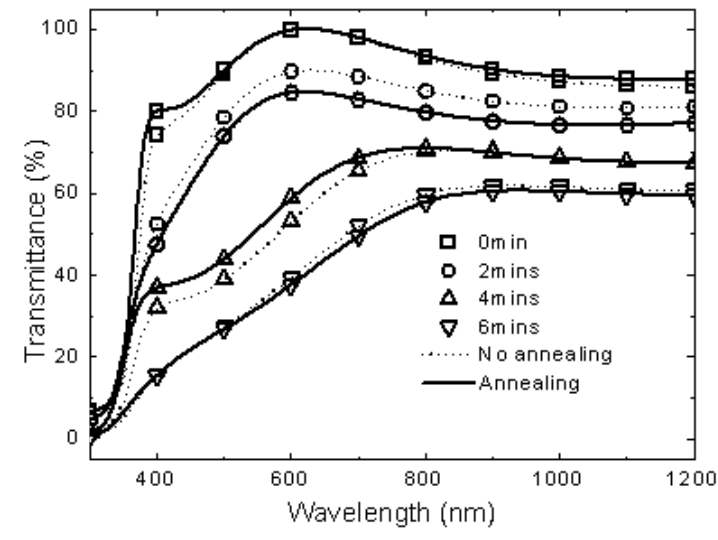

Fig. 8. The transmittance spectra of AZO deposited at different aluminum co-sputtering time

Fig. 8 shows the transmittance of the AZO thin films obtained by co-sputtering method with added aluminum. Once can see that the more DC sputter time on the Al target, the films exhibit less transparent properties. Also annealed thin films have less significance effects on the transmission spectra. Fig. 9 show the $(\alpha h v)^{2}$ curves versus photon energy of the AZO in dependence of $\mathrm{Al}$ sputtering time. With the linear fit at higher photon energy, we can extrapolate the direct band gap of these films. This value is at the range between $3.2 \mathrm{eV}$ and $3.4 \mathrm{eV}$, which is clearly smaller than that value of thin films deposited under the oxygen reactive sputtering condition.

The effect of the annealing process on the sheet resistance of AZO thin films doped more aluminum is showed on Fig. 10. For the film with no added aluminum, which is corresponded to the 0 min of the DC sputter time, the sheet resistance could be hardly measured. But for the films annealed under the hydrogen atmosphere this value is about $6 \mathrm{k} \Omega / o$. As the DC sputter time on the 
Al target increases, the value of sheet resistance decreases. And the annealed films always exhibit smaller sheet resistance.

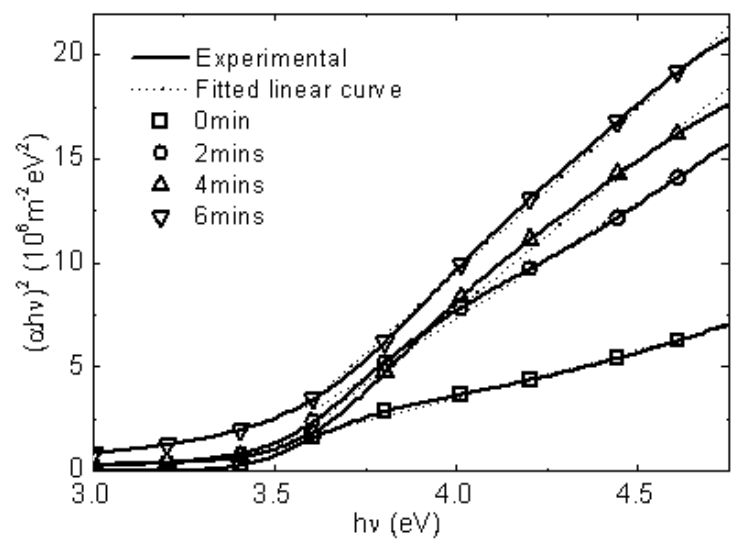

Fig. 9. The extrapolation of optical bandgap of AZO vs aluminum co-sputtering time

Fig. 11 shows the calculated resistivity of the AZO thin films with added aluminum by the co-sputtering method. As the DC sputter time on the Al target increases more, the resistivity of AZO films greatly decreases from $10^{-1} \Omega . \mathrm{cm}$ to about $10^{-2} \Omega . \mathrm{cm}$. By putting together the transmittance spectra and the resistivity of the AZO thin films, one can see that with 2 min of the DC sputter time, the film possesses optimum properties: a good conductance, with the resistivity about $1.3 \times 10^{-2} \Omega . \mathrm{cm}$, and a good transparency, with the transmission higher than $80 \%$. This condition can be used for further studies and shows highly potential applications in thin film solar cell as transparent conductive oxide layers.

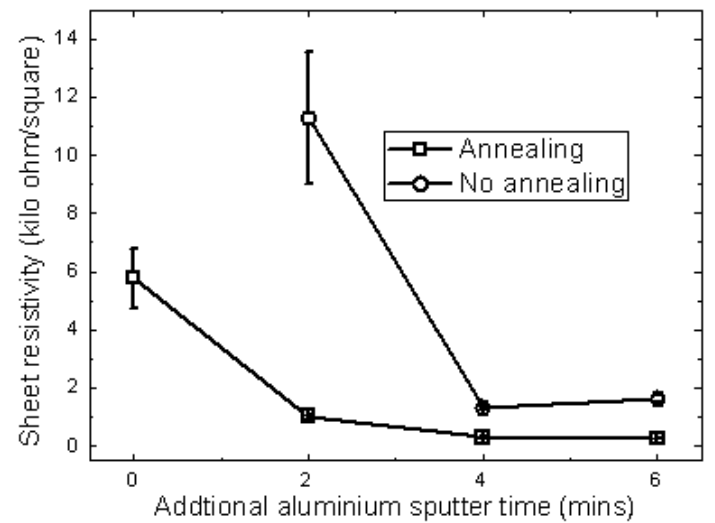

Fig. 10. The effect of annealing on the sheet resistance of AZO thin films

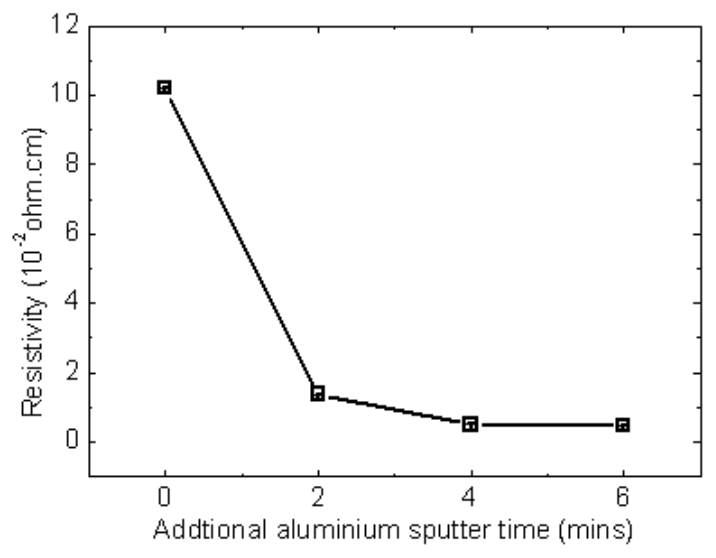

Fig. 11. The dependence of resistivity as function of aluminum cosputtering time 


\section{CONCLUSION}

A study on the sputtering conditions affecting to the properties of AZO thin films is presented; started by a simple sputtering method on single AZO target, then followed by a complicated oxygen reactive co-sputtering and added aluminum co-sputtering during limited numbers of time. The AZO thin films showed high transparency properties for oxygen reactive co-sputter series but very low conductivity. The AZO thin films have optimized TCO properties for the condition of 2 min of the DC sputter time on the Al target followed by annealing under a hydrogen atmosphere. At these conditions, a transmittance higher than $80 \%$ for the wavelength range from $400 \mathrm{~nm}$ to $1200 \mathrm{~nm}$, and a resistivity of $1.3 \times 10^{-2} \Omega$.cm were obtained. These AZO thin films serving as a n-type TCO layer may be suggested to applications in the low-cost semiconducting oxide based solar cells.

\section{ACKNOWLEDGEMENTS}

The authors greatly acknowledge the financial support of Vietnam National University Hanoi under the project "Study and fabrication of $\mathrm{CuFeO}_{2}$ delafossite thin film for applications in making solar cells" through the contract number QG.14.24.

\section{REFERENCES}

[1] Y. S. Jung, H.W. Choi and K. H. Kim, J. Korean Phys. Soc. 55 (2009) 1945

[2] J. Song,Y. He,J. Chen, D. Zhu, Z. Pan, Y. Zhang and J. Wang, Journal of Electronic Materials, 41 (2011) 431

[3] A. Tsukazaki, A. Ohtomo, T. Onuma, M. Ohtani, T. Makino, M. Sumiya, K. Ohtani, S. F. Chichibu, S. Fuke, Y. Segawa, H. Ohno, H. Koinuma, and M. Kawasaki, Nature Materials 4 (2005) 42

[4] [] Y. I. Alivov, E. V. Kalinina, A. E. Cherenkov, D. C. Look, B. M. Ataev, A. K. Omaev, M. V. Chukichev and D. M. Bagnall, Appl. Phys. Lett. 83 (2003) 4719

[5] Y. Liu, Y. Li, and H. Zeng, Journal of Nanomaterials 2013 (2013) 196521

[6] A. Illiberi, P.J.P.M. Simons, B. Kniknie, J. van Deelen, M. Theelen, M. Zeman, M. Tijssen, W. Zijlmans, H. L. A. H. Steijvers, D. Habets, A. C. Janssen and E.H.A. Beckers, Journal of Crystal Growth 347 (2012) 56

[7] P. Nunes, A. Malik, B. Fernandes, E. Fortunato, P. Vilarinho and R. Martins, Vacuum 52 (1999) 45

[8] M. Hiramatsu, K. Imaeda, N. Horio and M. Nawata, J. Vac. Sci. Technol. A 16 (1998) 669

[9] A. A. Alnajjar, Advances in Condensed Matter Physics 2012 (2012) 682125

[10] T. Minami, K. Oohashi, S. Takata T. Mouri and N. Ogawa, Thin Solid Films 193-194 (1990) 721

[11] N. N. Dinh, T. Q. Trung, L. K. Binh, N. D. Khoa, V. T. M. Thuan, VNU J. Science, Mat. Phys. 24 (2008) 16

[12] N. Akin, U. C. Baskose, B. Kinaci, M. Cakmak, S. Ozcelik, Appl. Phys. A 119 (2015) 965

[13] N. F. Mott and E. A. Davis, Electronic Process in Non-Crystalline Materials, Oxford University Press, Oxford, UK, 1979. 